\title{
Effects of caffeoylxanthiazonoside on airway inflammation in an allergic asthma mice model
}

\author{
Qian Wu, Hui Wang, Xiaowen Che*, Wei Wang \\ The Second Hospital of Shandong University, Jinan 250033, China \\ *For correspondence: Email: xiaowenchede@163.com; Tel: +86- 0531-88197777
}

\begin{abstract}
Purpose: To investigate the inhibitory effects of caffeoylxanthiazonoside (CYT) on airway inflammation in mice and its mechanism of action.

Methods: An allergic asthma mice model was established by intraperitoneal injection and aerosol nebulization with ovalbumin (OVA). After treatment with CYT, the blood and bronchoalveolar lavage fluid (BALF) were collected from the mice. The leukocytes were classified and counted with Giemsa solution. Enzyme-linked immunosorbent assay (ELISA) was used to determine the serum levels of IgE, and IL-4, IL-5, IL-13 and IFN-y in the BALF of mice. Lung tissues were obtained from the mice and MUC5AC protein expression was measured by western blot.

Results: CYT significantly decreased the serum level of IgE in asthmatic mice. Inflammatory cells in BALF of mice were markedly reduced $(p<0.05)$ by CYT treatment at varying doses $(10,20$, and 40 $\mathrm{mg} / \mathrm{kg}$ ). Treatment with CYT also significantly suppressed the cytokines of IL-4, IL-5 and IL-13 and increased the IFN-y in the BLAF of OVA-induced allergic asthma mice $(p<0.05)$. Western blot results indicate that CYT treatment significantly decreased the expression of MUC5AC protein in the lung tissues of asthmatic mice. In addition, no significant effects on the body weight of the mice were found after CYT treatment.

Conclusion: Caffeoylxanthiazonoside inhibits airway inflammation in allergic asthma mice by altering Th1/Th2 via re-balancing of related cytokines and downregulation of lung MUC5AC protein expression. Therefore, this compound can potentially be developed for the therapeutic management of inflammation in allergic asthma.
\end{abstract}

Keywords: Caffeoylxanthiazonoside, Ovalbumin, Airway inflammation, Allergic asthma

\begin{abstract}
This is an Open Access article that uses a fund-ing model which does not charge readers or their institutions for access and distributed under the terms of the Creative Commons Attribution License (http://creativecommons.org/licenses/by/4.0) and the Budapest Open Access Initiative (http://www.budapestopenaccessinitiative.org/read), which permit unrestricted use, distribution, and reproduction in any medium, provided the original work is properly credited.
\end{abstract}

Tropical Journal of Pharmaceutical Research is indexed by Science Citation Index (SciSearch), Scopus, International Pharmaceutical Abstract, Chemical Abstracts, Embase, Index Copernicus, EBSCO, African Index Medicus, JournalSeek, Journal Citation Reports/Science Edition, Directory of Open Access Journals (DOAJ), African Journal Online, Bioline International, Open-J-Gate and Pharmacy Abstracts

\section{INTRODUCTION}

Asthma is a chronic airway inflammatory disease with the characterizations of reversible airflow obstruction, goblet cell and smooth muscle hyperplasia, increased mucus production, hyperactivity and ultrastructural remodeling of the airways [1,2]. The prevalence of asthma in the developed countries is approximately $10 \%$ of the population [3]. Inhaled glucocorticoids and $\beta_{2^{-}}$ agonists are common pharmacological treatments for asthma [4]. However, the effectiveness of these agents is not satisfactory for numerous patients [5]. Therefore, it is imperative to discover new agents which are 
well-tolerated and effectively mitigate the symptoms of asthma.

Xanthium strumarium $\mathrm{L}$. (XSL), belonging to the Asteraceae family, is a widely used medicinal plant in China [6]. Its fruits, called "Cangerzi" in Chinese, have been used for treating inflammatory diseases including allergic rhinitis, tympanitis, urticaria, arthritis and ozena [7]. Various compounds have been found in the the fruits of XSL, includings flavonoids, saponins, caffeyolquinic acids, caffeic acids, and sesquiterpene lactones [8]. Caffeoylxanthiazonoside (CYT, Figure 1) is an active thiazinedione heterocyclic compound isolated from the fruits of XSL, and investigations have shown that CYT possesses favorable therapeutic effects on allergic rhinitis, sepsis, and chronic heart failure $[9,10]$. The aim of this study was ti determine the effects of CYT on airway inflammation in an allergic asthma mice model.<smiles>CC1(C)C(COC2OC(CO)C(O)C(O)C2OC(=O)/C=C/c2ccc(O)c(O)c2)=CC(=O)C2=C1SCC(=O)N2</smiles>

Figure 1: Structure of CYT

\section{EXPERIMENTAL}

\section{Chemicals and reagents}

Caffeoylxanthiazonoside (purity $\geq 98 \%$ ) was purchased from Shanghai PureOne Biotechnology (Shanghai, China). Ovalbumin (OVA, $\geq 90 \%$ ) was obtained from Sigma Aldrich (St Louis, MO, USA). Interleukin (IL-4), IL-5, IL13, interferon (INF) $-\gamma$ and Immunoglobulin $E$ (IgE) ELISA kits were obtained from $R$ \& $D$ Systems (Minneapolis, MO,USA). Dexamethasone was purchased from Cisen Pharmaceutical Co, Ltd (Jinan, China). The primary antibody against musin 5AC (MUC5AC) and secondary antibodies were obtained from Abcam (Cambridge, MA).

\section{Animals}

Female BALB/c mice (Six-week-old, $19 \pm 1 \mathrm{~g}$ ) were purchased from SLAC Laboratory Animal
Co. Ltd. (Shanghai, China). Animals were housed in a condition-controlled room with 12:12$h$ light-dark cycle $\left(21 \pm 2^{\circ} \mathrm{C}\right)$ and were free access to food and water.. The animal experiments in the present study were in accordance with the Guide for the Care and Use of Laboratory Animals [11] and were approved by the institutional Ethics Committee on Animal Use (no. 2017KW124) in The Second Hospital of Shandong University (Ji'nan, China).

\section{Model and groups}

The allergic asthma model was induced by OVA using a previously described method with some modifications [12]. After one week's acclimatization, mice were randomly divided into 6 groups $(\mathrm{n}=12)$ : Normal control group; negative control group; DEX group $(5 \mathrm{mg} / \mathrm{kg}$ ); and varying doses of CYT groups $(10,20$, and 40 $\mathrm{mg} / \mathrm{kg}$ ). The mice were sensitized by intraperitoneal injection (i.p.) with OVA $(20 \mu \mathrm{g})$ on day 7 and 14 . At the day 15 to 21 , mice were challenged with aerosol nebulization with $1 \%$ OVA (dissolved in PBS) for $30 \mathrm{~min}$ each day. Meanwhile, mice in CYT groups were administered with CYT (i.p.) once a day during this period. Normal control group received normal saline at each step. At day 22, blood were collected by extirpating eyeball and the serum were prepared by centrifugation ( 3500 rpm, $10 \mathrm{~min}$ ) at $4{ }^{\circ} \mathrm{C}$.

\section{Preparation of bronchoalveolar lavage fluid (BALF)}

The left lungs of the mice were lavaged with 0.5 $\mathrm{mL}$ normal saline to obtain the BALF. After centrifugation (1000 rpm) for $10 \mathrm{~min}$ at $4{ }^{\circ} \mathrm{C}$, the cell culture supernatants were collected for the determination of inflammatory cytokines. The precipitated cells were stained with Giemsa solution, and the number of total cells, neutrophils, eosinophils (EOS) and lymphocytes in BALF were classified and counted based on the morphology and staining profile.

\section{Enzyme-linked immunosorbent assay (ELISA)}

The serum levels of $\mathrm{IgE}$, and inflammatory cytokines including IL-4, IL-5, IL-13 and IFN-y in the BALF of mice were measured by commercial ELISA kits according to the manufacturer's instructions.

\section{Western blot analysis}

Lung tissues of mice were surgically collected and the total proteins were extracted. The total protein $(50 \mu \mathrm{g})$ was separated by $8 \%$ sodium 
dodecyl sulfate - polyacrylamide gel electropheresis (SDS-PAGE), and then transferred onto a polyvinylidene fluoride (PVDF) membrane. After blocking with $5 \%$ skimmed milk for $1 \mathrm{~h}$, and the PVDF was incubated with different primary antibodies overnight at $4{ }^{\circ} \mathrm{C}$, respectively. Subsequently, the membrane was incubated with horseradish peroxidase labelled secondary antibodies for $1 \mathrm{~h}$ at room temperature. The protein bands were visualized by using Electro-Chemi-Luminescence (ECL) reagents.

\section{Statistical analysis}

SPSS 17.0 software (IBM Corp., Armonk, NY) was used to analyze the data. The data are expressed as mean \pm standard deviation. Statistical signifcance between different groups was compared using student's $t$-test or variance analysis. $P<0.05$ was regarded as statistically signifcant.

\section{RESULTS}

\section{Concentration of IgE in mouse serum}

As shown in Figure 2, the IgE level in the serum of negative control group was significantly increased $(p<0.01)$, when compared with those of normal control group. After the treatment of DEX, the serum level of $\mathrm{IgE}$ in the mice significantly decreased compared with negative control group. More importantly, the serum IgE level of the CYT-treated groups was also decreased $(p<0.01)$ compared with negative control group at doses of 10,20 and $40 \mathrm{mg} / \mathrm{kg}$.

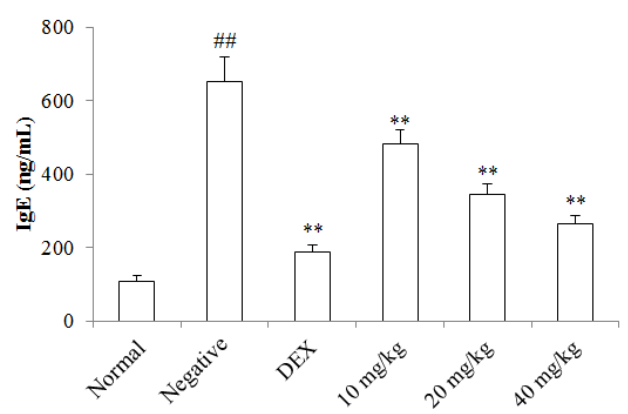

Figure 2: Serum level of IgE in mice; \#\#p < 0.01, compared with the normal control group; ${ }^{* *} p<0.01$, compared with negative control group

\section{Inflammatory cells in BALF}

The number of total cells, neutrophils, EOS and lymphocytes were counted to evaluate the effects of CYT on the influx of inflammatory cells. The number of inflammatory cells in the BALF of mice was markedly increased after the model was established (Figure 3). DEX treatment significantly reduced the number of inflammatory cells in the BALF $(p<0.01)$. Interestingly, CYT at different doses also had significant inhibitory effect on inflammatory cells in mice BALF (Figure $3)$.
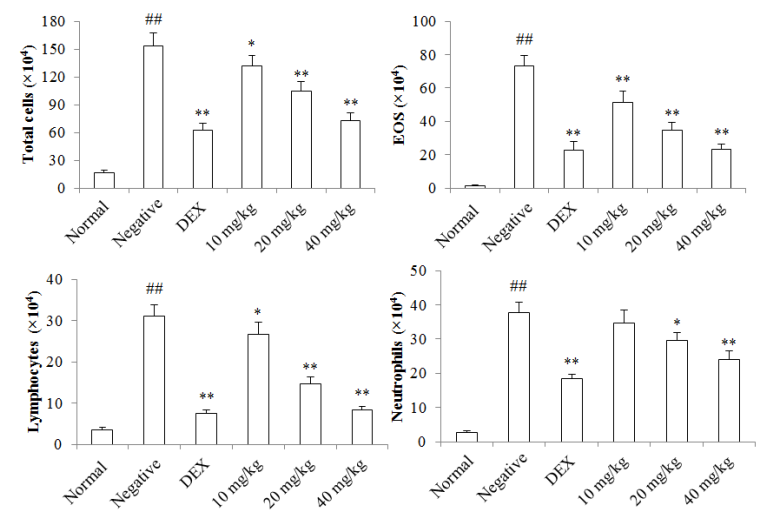

Figure 3: Effect of CYT on inflammatory cell number in BALF; \#p< 0.01, compared with the normal control group; ${ }^{*} p<0.05$ and ${ }^{* *} p<0.01$, compared with the negative control group

\section{Inflammatory cytokines production in BALF}

Compared with the normal control group, IL-4, IL5 and IL-13 levels of BALF increased, whereas IFN-y level decreased in negative control group (Figure 4). Treatment with DEX and different doses of CYT (10, 20 and $40 \mathrm{mg} / \mathrm{kg}$ ) significantly suppressed cytokines (IL-4, IL-5 and IL-13) compared with negative control group $(p<0.01)$. Furthermore, IFN-y level in BALF of DEX- and CYT-treated groups (20 and $40 \mathrm{mg} / \mathrm{kg}$ ) was higher than that of negative control group.

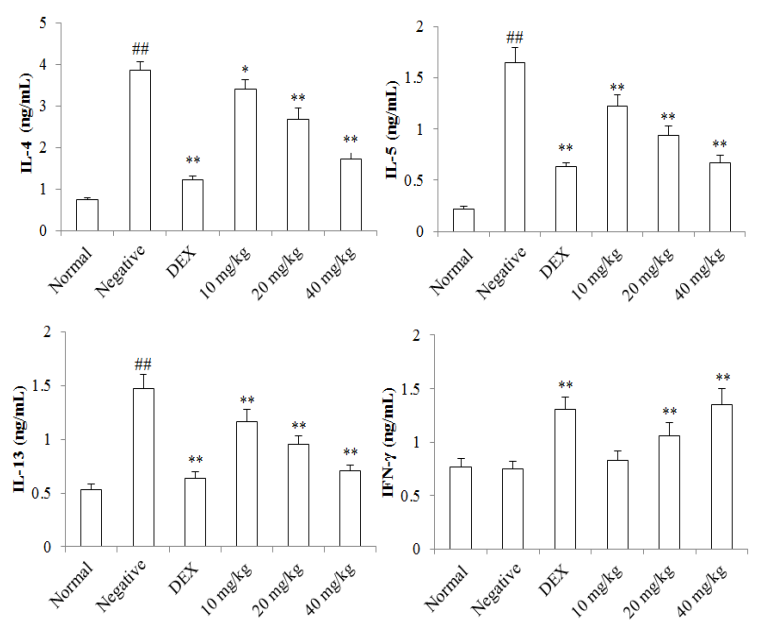

Figure 4: Levels of cytokines (IL-4, IL-5, IL-13 and IFN-Y) in BALF; \#\#p $<0.01$, compared with normal control group; ${ }^{*} p<0.05$ and ${ }^{* *} p<0.01$, compared with negative control group 


\section{Effect of CYT on expression of MUC5AC protein}

To further explore the mechanism of action of CYT in allergic asthma, the expression of MUC5AC protein was determined by western blot. As shown in Figure 5, the MUC5AC protein was markedly upregulated in negative control group when compared with normal control group. Both DEX and different doses of CYT significantly downregulated the protein expression of MUC5AC in lung tissues of mice, compared with negative control group $(p<0.01)$.

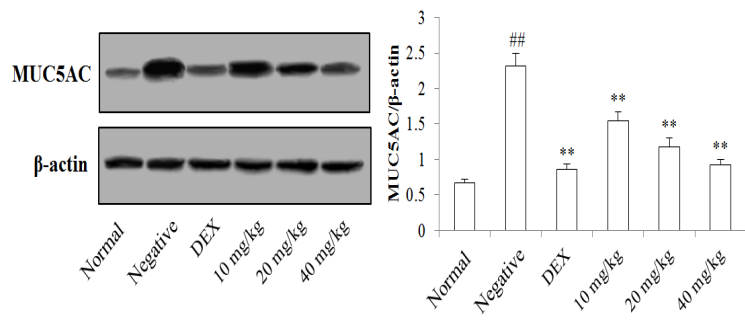

Figure 5: MUC5AC protein expression in lung tissues of mice; $\# \# p<0.01$, compared with the normal control group; ${ }^{* *} p<0.01$, compared with the negative control group

\section{Effect of CYT on body weight of mice}

The body weight of mice was used to evaluate the toxicity of CYT. As can be seen from Figure 6 , the body weight of DEX group was significantly lower than that of normal control group. However, there was no significant difference in body weight for CYT-treated and normal control groups. These results indicate that CYT did not exert significant toxicity in mice.

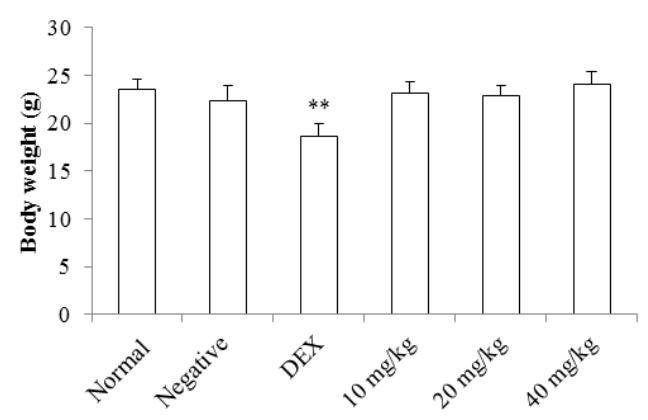

Figure 6: Effect of CYT on mouse body weight; ${ }^{* *} p<$ 0.01 , compared with normal control group

\section{DISCUSSION}

In the present study, the protective effects of CYT on airway inflammation were investigated in an OVA-induced allergic asthma mice model. The results indicate that CYT significantly suppressed the airway inflammation in allergic asthma. Specifically, CYT significantly downregulated the expression of MUC5AC protein in mouse lung tissues, but had no significant effect on the body weight of the mice.

Asthma is a Th2 cell-associated lung inflammatory disease which is characterized by eosinophil recruitment, $\lg \mathrm{E}$ increase, inflammatory cytokines release, mucus hypersecretion and bronchoconstriction [13]. The recruitment of eosinophils into the airways is a characteristic of asthma, and transmigration of leukocytes into the airways can be regulated by cytokines such as IL-4, IL-5 and IL-13 [14]. The Th1 (IFN-y) and Th2 (IL-4, IL-5 and IL-13) cytokines are reported to be closely associated with the pathogenesis of asthma [15]. The alteration of Th1 and Th2 cytokines induces secretion of allergen-specific IgE, overproduction of airway eosinophilia and mucus secretion [16]. In the present study, CYT treatment reduced the leukocytes number (especially eosinophils) in the BALF, suppressed the IgE production in the serum, decreased the Th1 cytokines (IL-4, IL-5 and IL-13) expression and increased the Th2 cytokine (IFN-y) expression. The results indicate that CYT may inhibit allergic inflammation in the OVA-induced allergic asthma mice model by altering Th1/Th2 via re-balancing the related cytokines.

It has been reported that mucus contains a lot macromolecules, and mucins are the major components of mucus. As an important gelforming mucin, MUC5AC is up-regulated when airway inflammation occurs [17]. In asthmatic patients, up-regulation of MUC5AC production contributes to mucous plugs and airflow obstruction [18]. In the present study, CYT inhibited allergic inflammation and this was linked to the downregulation of MUC5AC protein expression.

\section{CONCLUSION}

Caffeoylxanthiazonoside significantly inhibits airway inflammation by altering Th1/Th2 via rebalancing of related cytokines and downregulation of lung MUC5AC protein expression in allergic asthma mice. Therefore, this compound may be developed into a suitable drug for inflammation in allergic asthma.

\section{DECLARATIONS}

\section{Acknowledgement}

This study was supported by Natural Science Fund of Shandong Province, Training Fund (no. ZR2017PH061), Natural Science Fund of Shandong Province (no. ZR2014HM054) and 
Youth Fund of Second Hospital of Shandong University (no. Y2013010007).

\section{Conflict of interest}

No conflict of interest is associated with this work.

\section{Contribution of authors}

We declare that this work was done by the authors named in this article and all liabilities pertaining to claims relating to the content of this article will be borne by them. Wei Wang conceived and designed the study; Hui Wang and Xiaowen Che collected and analyzed the data, Qian Wu wrote the manuscript. All authors have read and approved the manuscript for publication in this journal.

\section{Open Access}

This is an Open Access article that uses a funding model which does not charge readers or their institutions for access and distributed under the terms of the Creative Commons Attribution License (http://creativecommons.org/licenses/by/ 4.0) and the Budapest Open Access Initiative (http://www.budapestopenaccessinitiative.org/rea d), which permit unrestricted use, distribution, and reproduction in any medium, provided the original work is properly credited.

\section{REFERENCES}

1. Gong $F$, Zhu HY, Zhu J, Dong QJ, Huang X, Jiang DJ. Circulating CXCR5+CD4+ $T$ cells participate in the $\operatorname{lgE}$ accumulation in allergic asthma. Immunol Lett 2018; 197: 9-14.

2. Schmudde I, Laumonnier $Y$, Köhl J. Anaphylatoxins coordinate innate and adaptive immune responses in allergic asthma. Semin Immunol 2013; 25(1): 2-11.

3. Zhou $P$, Wu $T$, Jin $X, L i J$, Yan $H$, Zhou L, Huang $Y$, Wang J, Zhou $H$, Zhu $X$, et al. FcyRIIIA Negatively Impacts Humoral Immune Responses but Not Overall Lung Inflammation in an Ovalbumin-Induced Allergic Asthma Mouse Model. Int Arch Allergy Immunol 2018; 176(1): 61-73.

4. Movassagh H, Shan L, Duke-Cohan JS, Chakir J, Halayko AJ, Koussih L, Gounni AS. Downregulation of semaphorin $3 E$ promotes hallmarks of experimental chronic allergic asthma. Oncotarget 2017; 8(58): 9895398963.

5. Xu W1, Hu M, Zhang $Q, Y u$ J, Su W. Effects of anthraquinones from Cassia occidentalis $L$. on ovalbumin-induced airways inflammation in a mouse model of allergic asthma. J Ethnopharmacol 2018; 221: 1-9.
6. Lin B, Zhao $Y$, Han $P$, Yue W, Ma XQ, Rahman K, Zheng $C J$, Qin LP, Han T. Anti-arthritic activity of Xanthium strumarium $L$. extract on complete Freund's adjuvant induced arthritis in rats. J Ethnopharmacol 2014; 155(1): 248-255.

7. Jiang $H$, Yang $L$, Xing $X$, Yan $M$, Guo $X$, Yang $B$, Wang $Q$, Kuang H. HPLC-PDA Combined with Chemometrics for Quantitation of Active Components and Quality Assessment of Raw and Processed Fruits of Xanthium strumarium L. Molecules 2018; 23(2): pii: E243.

8. Peng W, Ming QL, Han P, Zhang QY, Jiang YP, Zheng $C J$, Han $T$, Qin LP. Anti-allergic rhinitis effect of caffeoylxanthiazonoside isolated from fruits of Xanthium strumarium L. in rodent animals. Phytomedicine 2014; 21(6): 824-829.

9. Yang B, Wang F, Cao H, Liu G, Zhang Y, Yan P, Li B. Caffeoylxanthiazonoside exerts cardioprotective effects during chronic heart failure via inhibition of inflammatory responses in cardiac cells. Exp Ther Med 2017; 14(5): 4224-4230

10. Wang YH, Li TH, Wu BQ, Liu H, Shi YF, Feng DY. Protective effects of caffeoylxanthiazonoside isolated from fruits of Xanthium strumarium on sepsis mice. Pharm Biol 2015; 53(9):1367-1371.

11. "Principles of Laboratory Animal Care" (NIH publication no. 85-23, revised 1985). Available from: http://grants 1.nih.gov/grants/olaw/references/phspol.htm

12. Lee MY, Shin IS, Jeon WY, Lim HS, Kim JH, Ha H. Pinellia ternata Breitenbach attenuates ovalbumininduced allergic airway inflammation and mucus secretion in a murine model of asthma. Immunopharmacol Immunotoxicol 2013; 35(3):410-418.

13. Chen $H, X u X$, Cheng $S, X u Y$, Xuefei Q, Cao Y, Xie J, Wang $C Y, X u Y$, Xiong $W$. Small interfering RNA directed against microRNA-155 delivered by a lentiviral vector attenuates asthmatic features in a mouse model of allergic asthma. Exp Ther Med 2017; 14(5): 4391 4396.

14. Lloyd CM, Hessel EM. Functions of T cells in asthma: more than just $T(H) 2$ cells. Nat Rev Immunol. 2010; 10(12): 838-848.

15. Nieto-Fontarigo JJ, Salgado FJ, San-José ME, Cruz MJ, Casas-Fernández A, Gómez-Conde MJ, ValdésCuadrado L, García-González MÁ, Arias P, Nogueira M, et al. The CD14 (-159 C/T) SNP is associated with sCD14 levels and allergic asthma, but not with CD14 expression on monocytes. Sci Rep 2018; 8(1): 4147.

16. Matheson MC, Reece JC, Kandane-Rathnayake RK, Tang ML, Simpson JA, Feather IH, Southey MC, Tsimiklis H, Hopper JL, Morrison SC, et al. Mouldsensitized adults have lower Th2 cytokines and a higher prevalence of asthma than those sensitized to other aeroallergens. Allergy. 2016; 71(12): 1701-1711.

17. Wang $X, L i$ Y, Luo D, Wang $X$, Zhang Y, Liu Z, Zhong N, Wu $M$, Li G. Lyn regulates mucus secretion and MUC5AC via the STAT6 signaling pathway during allergic airway inflammation. Sci Rep 2017; 7: 42675. 
Wu et al

18. Evans CM, Raclawska DS, Ttofali F, Liptzin DR, Fletcher $A A$, Harper DN, McGing MA, McElwee MM, Williams OW, Sanchez E, et al. The polymeric mucin Muc5ac is required for allergic airway hyperreactivity. Nat Commun 2015; 6: 6281. 